\title{
Clinical Profile of Chronic Heart Failure in Hospitalized Type 2 Diabetic Patients
}

\author{
Shahana Parveen ${ }^{1}$, AMB Safdar ${ }^{2}$, Faria Afsana ${ }^{3}$, AKM Mohibullah $^{4}$, Ramendra Nath Sarker $^{5}$
}

\begin{abstract}
:
Objective: To see the clinical profile of chronic heart failure in hospitalized type 2 diabetic subjects.

Method: This cross-sectional study was carried out on a total of 100 type 2 diabetic patients with chronic heart failure, in the Department of Cardiology, BIRDEM, over a period of six months between July to December 2012.

Results: The mean age of the study subjects was $60.9 \pm 11.7$ years with male to female ratio being roughly $2: 1$. The mean duration of diabetes mellitus was 9.15 years. Among the study subjects $72 \%$ were on insulin and $18 \%$ on oral hypoglycemic agents; $10 \%$ were on combined insulin and oral hypoglycemic agent. Dyspnea and cough were invariably present. About $88 \%$ subjects had edema, $39 \%$ raised JVP, and $13 \%$ murmur. Bilateral basal crepitation was found in $56 \%$ cases. While mean fasting blood glucose (FBG), postprandial blood glucose (PPBG) level and $\mathrm{HbA} 1 \mathrm{C}$ were $10 \mathrm{mmol} / \mathrm{l}, 16.7 \mathrm{mmol} / \mathrm{l}$ and $9.9 \%$ respectively, mean serum creatinine was 2.07 $\mathrm{mg} / \mathrm{dl}$. Among study subjects, raised ESR (48\%), elevated WBC count (50\%) and raised BNP level $(64.6 \%)$ were seen. Chest X- ray revealed cardiomagaly (70\%), reticulonodular shadow in both lung fields $(11 \%)$ and septal thickening (15\%). ECG findings of the patients were old infarct $(72 \%)$, IHD (66\%), RV hypertrophy $(40 \%)$ and arrhythmia (17\%). Most common echocardiographic findings of the subjects were regional wall motion abnormalities (78\%), Mild LV systolic dysfunction (64\%) with Grade-I diastolic dysfunction being $70 \%$ and moderate to severe pulmonary arterial hypertension being $40 \%$.
\end{abstract}

Conclusion: Raised BNP level, presence of old infarct in ECG and regional wall motion abnormalities in echocardiography are the common clinical findings among patients with chronic heart failure.

Key points: Chronic Heart Failure, Clinical Profile, Type 2 Diabetes.

\section{Introduction}

Diabetes Mellitus is a chronic or persistent hyperglycemia due to either deficiency of insulin secretion or insulin action or both as a result of genetic \& environmental factors leading to severe complications including cardiovascular disease, renal disease amd blindness. ${ }^{1}$ Epidemiological evidence suggest that incidence of diabetes is increasing worldwide. Type 2 Diabetes Mellitus is now one of the most common non-communicable diseases globally. 2,3 The International Diabetic Federation estimates in 2010 that approximately
285 million people of the world have been affected by diabetes with adult diabetics being 4.3 billion. Currently in Bangladesh, 7.1 million (prevalence $7.4 \%$ ) adult people are suffering from diabetes. ${ }^{4}$

Heart failure is a complex clinical syndrome that results from structural or functional cardiac disorder and impairs the ability of the ventricle to fill with or eject blood. ${ }^{5}$ Extrapolated statistics revealed that in Bangladesh approximate prevalence of heart failure is 2.5 million among adult persons. ${ }^{6}$ The manifestation of heart failure are dyspnea, fatigue, reduced exercise tolerance \&

\section{Authors' information:}

${ }^{1}$ Dr. Shahana Parveen, MBBS, DEM, DCMO, Medicine OPD, BIRDEM General Hospital, Bangladesh.

${ }^{2}$ Dr. AMB Safdar, MBBS, FCPS (medicine) Associate professor, Department of Cardiology, BIRDEM General Hospital, Bangladesh.

${ }^{3}$ Dr. Faria Afsana, MBBS, DEM, MD, Assistant professor, Department of Endocrinology, BIRDEM General Hospital, Bangladesh.

${ }^{4}$ Prof. AKM Mohibullah, MBBS, MD, FRCP, FCCP, FACC, Professor \& Head, Department of Cardiology, BIRDEM General Hospital, Bangladesh.

${ }^{5}$ Dr. Ramendra Nath Sarker, D Card (BSMMU), Senior Consultant, (Cardiology), District Hospital, Gaibandha

Address of correspondence: Dr. Shahana Parveen, Cell Phone: +880 1716504101. Email:parveen_shahana@yahoo.com 
fluid retention leading to pulmonary congestion, peripheral edema. Important information concerning heart failure is suggested by the presenting symptoms. ${ }^{7}$ Acute and sub-acute presentations (days to week) are characterized primarily by shortness of breath at rest and/or with exertion. Also common are orthopnea, paroxysmal nocturnal dyspnea (PND), Cheynestokes respiration sometimes associated with marked weight loss. In right heart failure, right upper abdominal pain is manifested due to acute hepatic congestion and raised JVP. Patients with atrial and/or ventricular tachyarrhythmia may complain of palpitations with or without light headedness. ${ }^{8}$ Chronic presentation differs in that fatigue, anorexia, abdominal distention and peripheral edema may be more pronounced. Patients with advanced heart failure show evidence of a major decline in cardiac output and decrease in tissue perfusion. If severe left ventricular failure there is shifting of apical pulse and S3 gallop rhythm associated with left atrial enlargement. ${ }^{9}$

The prevalence of diabetes mellitus in heart failure population is close to $20 \%$ compared with $4-6 \%$ in control populations. ${ }^{10}$ Framingham study established the epidemiological link between heart failure and diabetes, which is due to poor glycemic control. ${ }^{11}$ There are different factors associated with heart failure in adult diabetic patients such as age, duration of diabetes, ischemic Heart Disease (IHD), elevated serum creatinine, microalbuminuria etc. The First demonstration of an increased risk of heart failure in patients with Type 2 DM was reported by Kannel and McGee based on data obtained from 20 years follow up of the Framingham Cohort. Long term follow up in UK prospective diabetes study (UKPDS) demonstrated that the incidence of heart failure in diabetic patients significantly co-relates with HbA1C levels. ${ }^{12}$ Action to control cardiovascular risk in diabetes (ACCORD) ${ }^{13}$ trial and Action in diabetes and vascular disease (ADVANCE) ${ }^{14}$ study shows that tight glycemic control improve cardiovascular risk factors such as dyslipidemia, hypertension, hypercoagulability, obesity and inflammation that are part of insulin resistance. There is a strong link between the existence of heart failure and diabetes. ${ }^{15}$ Both conditions are increasingly common. Hence the purpose of this study was to find the clinical features of chronic heart failure patients with type 2 diabetes mellitus.

\section{Method:}

This cross-sectional observational study was carried out to evaluate the clinical profile of 100 diabetic subjects suffering from chronic heart failure in the Department of Cardiology, BIRDEM General Hospital, Dhaka. The study included all consecutive type 2 diabetic patients aged $>40$ years, admitted into BIRDEM hospital with chronic heart failure. Informations collected were the subject's age, gender, medical history, clinical history of chronic heart failure with diabetes. Clinical examination, X-ray chest, ECG \& Echocardiographic tests were done to find type and features of chronic heart failure. The study was approved by Ethical Review Committee of BADAS. Data entry and analysis were done using SPSS for windows version 13.0.

In this study type 2 diabetes mellitus was considered when blood glucose in fasting state was $\geq 7.0 \mathrm{mmol} / \mathrm{L}$ and/or two hours after $75 \mathrm{gm}$ oral glucose drink $\geq 11.1 \mathrm{mmol} / \mathrm{L}$ or random blood sugar $\geq 11.1 \mathrm{mmol} / \mathrm{L}$ and/or $\mathrm{HbA} 1 \mathrm{C} \geq 6.5 \%$. Chronic heart failure was diagnosed when serum B-type natriuretic peptide (BNP) level was $>95$ $\mathrm{ng} / \mathrm{L}$, along with venous congestion, pulmonary oedeama and cardiomegaly in chest X-ray and/or left ventricular hypertrophy, previous myocardial infarction evident in ECG and/or echocardiography showing decreased left ventricular compliance and decreased relaxation of heart, regional wall motion abnormality, ejection fraction $<55 \%$ (according to Framingham Diagnostic Criteria for Heart Failure). ${ }^{11}$ Echocardiography was done by 2D method. Reference limits, values and partition values of left ventricular ejection fraction ${ }^{16}$, and severity of pulmonary hypertension ${ }^{17}$ were calculated by American Society of Echocardiography's guideline and Standard Committee. 


\section{Result:}

The mean age of the study subjects was $60.9 \pm$ 11.7 years (range: $47-64$ years) (Table I). Males were predominant $(66 \%)$ among the study subjects. The mean duration of diabetes mellitus was 9.1 years. Over one-third (38\%) of the subjects had diabetes for more than 15 years. Other than diabetes, the study subjects had dyslipidemia (72\%), hypertension (69\%), history of IHD (66\%) and CVD (19\%). Over 60\% were smoker. Over $70 \%$ of the study subjects were getting insulin, $18 \%$ were on oral hypoglycemic agents. Some $10 \%$ of the subjects were getting combined therapy (both insulin and oral hypoglycemic agents). Dyspnea and cough were invariably present. About $14 \%$ had complaints of chest pain and $6 \%$ presented with haemoptysis. Edema was predominant sign (88\%), followed by bilateral basal crepitation (56\%), raised JVP $(39 \%)$, murmur $(13 \%)$. Sixteen percent had crepitation in whole lung. Raised Troponin I level was observed in $12.9 \%$ (among 85 subjects) cases (Table II). Table III describes the different medicines that the study subjects were receiving for heart failure and Table IV describes the biochemical parameters

The chest $X$-ray findings (Figure 1 ) showed cardiomegaly to be $70 \%$, prominent pulmonary conus $34 \%$, prominent pulmonary arteries at both hila $40 \%$ and upper lobar diversion $20 \%$. Reticulonodular shadow in both lung fields $(11 \%)$ and septal thickening (15\%) were also observed. Common ECG findings were old infarct (72\%), IHD (66\%), LV hypertrophy (40\%), RV hypertrophy $(10 \%)$, LA hypertrophy $(6 \%)$, RA hypertrophy (4\%) and arrthythmia (17\%). Findings of echocardiography done by $2 \mathrm{D}$ method are described in Table V.

\section{TABLE I. Age distribution of the study subjects $(n=100)$}

$\begin{array}{lcc}\text { Age (yrs) } & \text { Frequency } & \text { Percentage } \\ <50 & 19 & 19 \\ 50-60 & 48 & 48 \\ >60 & 33 & 33\end{array}$

Mean age $=60.9 \pm 11.7$ years; range $(47-64)$ years.
TABLE II. Presenting symptoms \& Signs of chronic heart failure ( $n=100)$

$\begin{array}{lcc}\text { Symptoms \& Signs } & \text { Frequency } & \text { Percentage } \\ \text { Symptoms } & 100 & \\ \text { Dysponea } & 100 & 100.0 \\ \text { Cough } & 14 & 100.0 \\ \text { Chest Pain } & 6 & 14.0 \\ \text { Haemoptysis } & & 6.0 \\ \text { Signs } & 88 & \\ \text { Leg oedema } & 56 & 88.0 \\ \text { Bilateral basal crepitation } & 16 & 56.0 \\ \text { Whole lung crepitation } & 39 & 16.0 \\ \text { Raised JVP } & 13 & 39.0 \\ \text { Murmur in precordium } & & 13.0\end{array}$

\begin{tabular}{|c|c|c|c|}
\hline \multicolumn{4}{|c|}{$\begin{array}{l}\text { TABLE III. Medications received by the patients before } \\
\text { admission }(n=100)\end{array}$} \\
\hline Type of drugs & Drugs & requency & Percentage \\
\hline \multirow[t]{4}{*}{ Antihypertensive } & ACE inhibitor & 52 & 52.0 \\
\hline & ARB & 38 & 38.0 \\
\hline & Beta blocker & 22 & 22.0 \\
\hline & Calcium channel inhibitor & or 05 & 5.0 \\
\hline \multirow{2}{*}{ Antiischemic } & Glycerin trinitrate & 90 & 90.0 \\
\hline & Trimetazidine & 51 & 51.0 \\
\hline \multirow[t]{3}{*}{ Antiplatelet } & Aspirin & 40 & 40.0 \\
\hline & Clopidogrel & 50 & 50.0 \\
\hline & $\begin{array}{l}\text { Combination of aspirin } \\
\text { and clopidogrel }\end{array}$ & 10 & 10.0 \\
\hline \multirow[t]{2}{*}{ Diuretic } & Furosemide & 82 & 82.0 \\
\hline & $\begin{array}{l}\text { Combination of furosemide } \\
\text { and spironolactone }\end{array}$ & 18 & 18.0 \\
\hline \multirow[t]{2}{*}{ Antilipid } & Atorvastatin & 80 & 80.0 \\
\hline & Fenofibrate & 20 & 20.0 \\
\hline
\end{tabular}

\section{TABLE IV. : Biochemical parameters of the study subjects}

$\begin{array}{lcc}\text { Biochemical variables } & \text { Mean } \pm \text { SD } & \text { Minimum - Maximum } \\ \text { Cholesterol }(\mathrm{mg} / \mathrm{dl}) & 209 \pm 38.4 & 90-495 \\ \text { Triglyceride }(\mathrm{mg} / \mathrm{dl}) & 282 \pm 165 & 100-814 \\ \text { HDL }(\mathrm{mg} / \mathrm{dl}) & 34.22 \pm 12.67 & 13-57 \\ \text { LDL }(\mathrm{mg} / \mathrm{dl}) & 110 \pm 38.7 & 57.8-407 \\ \text { Serum creatinine } & 2.07 \pm 1.72 & 0.89-4.12 \\ \text { SGOT } & 36.64 \pm 19.25 & 14.67-58.38 \\ \text { SGPT } & 39.54 \pm 15.73 & 15.74-55.38 \\ \text { BNP } & 64.6 \pm 48.98 & 48.98-113.58 \\ \text { Troponin I } & 2.9 \pm 5.9 & 1.2-18.8\end{array}$




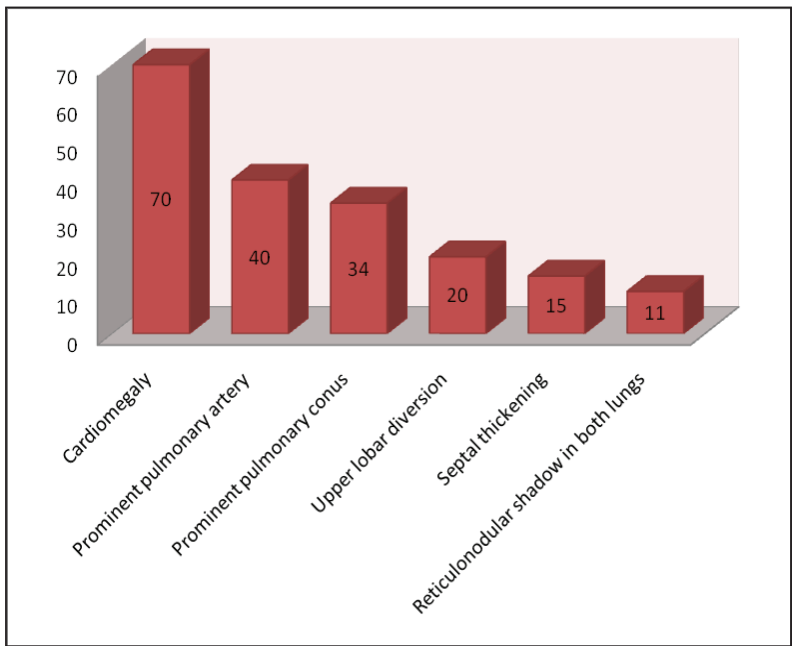

Figure 1: Common chest X-ray findings of the study subjects.

\begin{tabular}{|c|c|c|c|}
\hline \multicolumn{4}{|c|}{$\begin{array}{l}\text { TABLE V. Common Echocardiographic findings of the } \\
\text { patient }(n=100)\end{array}$} \\
\hline \multicolumn{2}{|c|}{ ECHO findings (Common) } & Frequency & Percentage \\
\hline \multicolumn{2}{|c|}{ Regional wall motion abnormality } & 78 & 78 \\
\hline \multicolumn{2}{|c|}{ Presence of valvular lesion } & 28 & 28 \\
\hline \multicolumn{4}{|c|}{ LV systolic function } \\
\hline Normal & $\geq 55 \%$ & 05 & 05 \\
\hline \multicolumn{4}{|c|}{ LV systolic dysfunction } \\
\hline Mild & $>45-54 \%$ & 64 & 64 \\
\hline Moderate & $>30-44 \%$ & 19 & 19 \\
\hline Severe & $\leq 30 \%$ & 12 & 12 \\
\hline \multicolumn{4}{|c|}{ Diastolic dysfunction } \\
\hline Grade I & & 70 & 70 \\
\hline Grade II & & 21 & 21 \\
\hline Grade III & & 09 & 09 \\
\hline \multicolumn{4}{|c|}{ Pulmonary hypertension ( mPAP mmHg) } \\
\hline Mild & $25-40 \mathrm{~mm}$ of $\mathrm{Hg}$ & 03 & 03 \\
\hline Moderate & $41-55 \mathrm{~mm}$ of $\mathrm{Hg}$ & 30 & 30 \\
\hline Severe & $>55 \mathrm{~mm}$ of $\mathrm{Hg}$ & 10 & 10 \\
\hline
\end{tabular}

\section{Discussion}

Epidemiological studies have demonstrated an increased risk of heart failure in diabetic populations. Various mechanisms may link diabetes mellitus to heart failure: firstly, associated comorbidities such as hypertension may play a role; secondly, diabetes accelerates the development of coronary atherosclerosis; thirdly, experimental and clinical studies support the existence of a specific diabetic cardiomyopathy related to microangiopathy, metabolic factors or myocardial fibrosis. In addition, it has been suggested that the deleterious impact of diabetes may be especially marked in patients with ischemic cardiomyopathy. ${ }^{3,15}$

The causes of chronic heart failure are difficult to analyze due to challenges in diagnosis, differences in populations and changing prevalence of causes with age. A study on 13000 healthy adults (both diabetic and non-diabetic) in the United States (the National Health and Nutrition Examination Survey (NHANES I) ${ }^{18}$ found ischemic heart disease $(62 \%)$, cigarette smoking $(16 \%)$ \& hypertension $(10 \%)$ as cause of heart failure. An Italian registry of over 6200 patients with heart failure showed ischemic heart disease $(40 \%)$, dilated cardiomyopathy (32\%) and hypertension (11\%) to be the causes of heart failuure. ${ }^{19}$ It was concluded in both studies that these risk factors demonstrated their significant presence in diabetic group than those in non-diabetic group in causing chronic heart failure. Dyslipidemia is often related to uncontrolled diabetes. . $^{5} 19$

Age and gender has effect on occurrence of chronic heart failure in diabetic subjects. A study reported that chronic heart failure occurs more in those over the age of 65 years. ${ }^{20}$ The present study also shows comparable ages of study subjects. A study reported that knowledge of the diabetic status might help to define the optimal therapeutic strategy for heart failure patients. ${ }^{21}$ Cornerstone treatments such as ACE inhibitors or beta-blockers appeared to be uniformly beneficial in diabetic and non-diabetic populations. However, in ischemic cardiomyopathy, the choice of the revascularization technique might differ according to diabetic status. Most of the diabetic subjects need diuretic drugs along with insulin or oral hypoglycaemic agents to control fluid overload and hyperglycaemia. Besides, they are prescribed antihypertensive, mostly ACE inhibitors, ARB, beta-blockers but calcium channel blockers are not prescribed usually as they cause fluid logging. When heart failure is associated with ischemic 
heart disease anti-ischemic and antiplatelet drugs are given. The present study revealed the similar drug management schedule.

Pfeffer et $\mathrm{al}^{22}$ reported that failure of the left ventricle causes congestion of the pulmonary vasculature and so the symptoms of chronic heart failure were predominantly respiratory in nature. The patients presented with dyspnea on exertion and in severe cases dyspnea at rest. Compromise of left ventricular forward function may result in symptoms of poor systemic circulation such as dizziness, confusion and cool extremities at rest. Dependent edema, pulmonary crepitation, increased jugular venous pressure were observed. Similar findings were observed in the present study where dyspnoea and cough were present in all subjects (100\%). ${ }^{23,24}$ Heart murmur may indicate the presence of valvular heart disease, either as a cause (e.g. aortic stenosis) or as a result (e.g., mitral regurgitation) of the heart failure. ${ }^{21,25,26}$ This was also seen in echocardiographic findings of the present study (presence of valvular lesion in $28 \%$ subjects). Physical examination revealed pitting peripheral oedema, raised jugular venous pressure, and parasternal heave. ${ }^{25}$ Similar signs were seen in the study. All these findings indicate significant compensatory increase in contraction strength of heart with fluid logging. Bilateral basal crepitation was observed in $56 \%$ of the subjects in this study. Long standing pulmonary edema and arteriolar atherosclerosis in pulmonary arteriole in diabetic subjects leads to pulmonary hypertension which might be mild to severe in characteristics. ${ }^{23,24}$ This situation was reflected in our study where indirect signs of pulmonary hypertension was observed in chest X-ray as prominent pulmonary conus (34\%), prominent pulmonary arteries at both hila (40\%), upper lober diversion (20\%) and direct signs as mild pulmonary arterial hypertension (31-50 $\mathrm{mm}$ of $\mathrm{Hg}$ ) in $30 \%$ subjects and moderate (51-70 $\mathrm{mm}$ of $\mathrm{Hg}$ ) pulmonary arterial hypertension in $10 \%$ subjects by echocardiography. A study ${ }^{27}$ showed that anaemia, raised ESR, increased total WBC count and elevated C-reactive protein were the commonest laboratory findings in chronic heart failure subjects. Risk factors identification for chronic heart failure in diabetic subjects was beyond the scope of this study as this is a descriptive study and a case-control study is needed for identification of risk factors.

\section{Conclusion}

Most of the type 2 diabetic subjects with chronic heart failure presented with dyspnoea, cough, and complaints of chest pain and swelling of leg. Raised Troponin I, presence of old infarct in ECG and regional wall motion abnormalities in echocardiography are the common features found in patients of chronic heart failure with type 2 diabetics.

\section{Reference}

1. Alberti KG \& Zimmet PZ. Defination, diagnosis and classification of diabetes mellitus and its complication. Dia Med 1998;15:539-53.

2. Concannon P, Rich SS \& Nepom GT. Genetics of Type 1 diabetes. N Eng J Med 2009;360:1646-54.

3. Holt RI, Cockram CS, Flyubjerg A \& Goldstein BJ. Text book of diabetes United kingdom: Blackwell publication. 2010;45-68.

4. IDF Diabetes Atlas 2015. International Diabetes Federation. $7^{\text {th }}$ Edition.

5. HO, Pinsky KK, Kannel WB \& Levy D. The epidemiology of heart failure. The Framinghum study. J Am Cardiolol 1993;17:22-26.

6. Michael R,MacDonald, Mark C, Petrie,Nathaniel M, Hawkins et al. Diabetes, Left ventricular systolic dysfunction and chronic heart failure. Eur Heart J 2008; 29(10): 1224-40.

7. Davie AP, Francies CM \& Carvana. Assessing the diagnosis in heart failure. Q J M 1997;90:335-38.

8. Heart failure society of America. Evaluation of patients for vascular dysfunction and heart failure. J Card Fail 2006;12:16-19.

9. Dickstein $K$, Solal A, Filippatos G, Mc. Murray J, Ponikowski P, Wilson PA et al. Task force for diagnosis and treatment of Acute and chronic Heart failure. Heart J Eur 2008;29:2388-42.

10. Bauters C, Lamblin N, Fadden E, Belle EV, Millaire A \& De Groote $P$. Influence of diabetes mellitus on heart failure risk and outcome. Cardiovascdiabetology 2003;2: 12-15.

11. Kanel W B \& Macgee D L. Diabetes and Cardiovascular disease. The Framingham study. JAMA 1979;241: 2035-38. 
12. Halman RR, Paul SK, Bethal MA, Mathew DRE \& Nail HA. 10 year follow up of intensive glucose control in type 2 DM. N Eng J Med 2008;359:1577-89.

13. Gerstein HC, Miller ME, Byington RP, Goff DC, Bigger JT, Base JB et al. Effects of intensive glucose lowering in type-2 Diabetes. N Eng J Med 2008;358:2545-59.

14. Patel A, MacMahon S, Chalmers J, Neal B \& Billot L. ADVANCE intensive blood glucose control and vascular outcomes in patient with type-2 diabetes. $N$ Eng J Med 2008; 358:2560-72.

15. Fisher $D$, Centers for disease control and prevention: Measuring Physical Activity Intensity Updated on May 26,2011 .

16. Lang RM, Bierig M, Devereux RB et al, Chamber quantification writing group: American Society of Echocardiography's guidelines and standard committee. Am Society of Echocardiography 2005;18:1440.

17. Echocardiography in Pul. Artery. Hypertension from diagnosis to prognosis $\mathrm{J}$ Am Society of Echocardiography 2013;26:1-14.

18. He J, Ogden LG, Bazzano LA \& Vupputuri S. Risk factors for congestive heart failure in US men and women: NHANES I epidemiologic follow-up study". Arch Intern Med 2001;161(7):996-1002.

19. Baldasseroni S, Opasich C, Gorini M \& Lucci D. Left bundle-branch block is associated with increased 1-year sudden and total mortality rate in 5517 outpatients with congestive heart failure: a report from the Italian network on congestive heart failure. Am Heart J 2002; 143(3):398-405.
20. Mc Murray J] \& Pfeffer MA. Heart failure. Lancet 2005; 365(9):1877-89.

21. Strömberg A \& Mårtensson J. Gender differences in patients with heart failure. Eur $J$ Cardiovasc Nurs 2003;2(1):7-18.

22. Pfeffer MA, Swedberg K, Granger CB, Held P, McMurray $\mathrm{JJV}$, Michelson EL, et al. Effects of candesartan on mortality and morbidity in patients with chronic heart failure: the CHARM-Overall Programme. Lancet $2003 ; 362: 759-66$

23. Hunter JG, Boon NA, Davidson S, Colledge NR \& Walker B. Davidson's principles \& practice of medicine (21 ed.). Elsevier/Churchill Livingstone. 2006;544.

24. McKee PA, Castelli WP, McNamara PM \& Kannel WB. The natural history of congestive heart failure: the Framingham study. N Engl J Med 1971;285(26):1441-46.

25. Bauters C, Lamblin N, Mc Fadden EP, Belle EV, Millaire A \& de Groote P. Influence of diabetes mellitus on heart failure risk and outcome. Cardiovascular Diab 2003; 2(1):1175-86.

26. Kearney MT, Nolan J, Lee AJ, Brooksby PW, Prescott R, Shah AM, et al. A prognostic index to predict long-term mortality in patients with mild to moderate chronic heart failure stabilised on angiotensin converting enzyme inhibitors. Eur J Heart Fail 2003;5:489-87.

27. Loscalzo A, Fauci J, Anthony S, Eugene B, Dennis L. Hauser K et al. Harrison's Principles of Internal Medicine (17ed.). McGraw-Hill Medical 2008,1447. 